\title{
Carbonization and Treatment the High Temperature Distortion of Thoriated Tungsten Cathode for High Power Electronic Tubes
}

\author{
Abdul Qader.D.Faisal* \\ Fadhil.A.Hashim. ** \\ Waddah J.Raouf $* * *$
}

\begin{abstract}
:
A metal mandrel was designed for manufacturing the cathodes of high power electron tube ( Tetrode ) used in broadcasting transmitting tubes type TH558 and CQS200.The cathodes were manufactured in the present work from thoriated tungsten wires $\left(2 \% \mathrm{ThO}_{2}-\mathrm{W}\right)$ with different diameters . These cathodes were carbonized in sequences of processes to determine the carbonization parameters (temperature, pressure, time, current and voltage). Then the carbonized cathodes dimension were accurately measured to determine the deviation due to the high temperature distortion effect at about $1800^{\circ} \mathrm{C}$.the distorted cathodes due to the carbonization process was treated when it was subjected inside the vacuum chamber and heat treated again. The carbonized cathode distortions as a function of temperature were measured in the range of $\left(1500^{\circ} \mathrm{C}-1800^{\circ} \mathrm{C}\right)$. The temperature was determined using an optical pyrometer and also calculated using Stephan's-Boltzmann relation.
\end{abstract}

Date of acceptance 18/3/2009

Key words: carbonization, high power electron tube, cathode distortion, thoriated tungsten.

\section{Introduction:}

Vacuum tube is an electronic device, simply consists of two electrodes (cathode and anode).The flow of electron from the cathode to anode occurred through a vacuum. There are three main types of electrodes in a vacuum tubes or thermo ionic valve. The cathode, anode and grid, all provide different but essential functions . Their construction is naturally different and there are some variations depends on the design of the tube and its applications. There is a variety of different types of cathode that are used in modern vacuum tubes. They differ in the construction of the cathode and the materials used. One of the major ways in which cathodes can be categorized is by the way they are heated .The first type used is the directly heated $[1,2]$.The second type of cathode is known as an indirectly heated. The earliest type of the cathode is known as a bright emitter cathode .This type of cathode uses a tungsten wire heated to a temperature between $2500 \mathrm{~K}$ and $2600 \mathrm{~K}[3,4]$. A further type of cathode is thoriated tungsten. This provides more emission, lower work function and very high life time than pure tungsten. Typically they run at a temperature of between $1900 \mathrm{~K}$ 2500K[4]. This type of cathode was used in high power transmitting tubes such those used for broadcasting [5].The other type of cathode is the oxide coated cathode. This used a mixture of barium and strontium carbonate on nickel, often with a trace of calcium. These are dissolved in organic solvent After mixing thoroughly, the solution is sprayed

\footnotetext{
*University of Technology.

**University of Thi-Qar..

***Ministry of Science and Technology.
} 
onto nickel substrates .The coated nickel is placed in a heated oxidizing environment. It operates at a much lower than the other types being in the region of $950 \mathrm{~K}-1050 \mathrm{~K}$ [6] .Tungsten cathode coated with a triple carbonate suspension was also used in vacuum tubes [7]. Thoriated tungsten $\left(\mathrm{ThO}_{2}-\mathrm{W}\right)$ still widely used in high power vacuum tubes for broadcasting and some other modern techniques such as plasma arc also use such material as electrodes [8].Thoriated tungsten cathodes decay rapidly because of thorium depletion at working temperatures of the vacuum tube [9]. Lots of efforts have been made to find alternatives to the thoriated tungsten cathodes in the past decades. $\mathrm{La}_{2} \mathrm{O}_{3}-\mathrm{Mo}$ (La-Mo in brief) as one of the attractive alternatives has been exhibited better performance [10]. Another alternative for thoriated tungsten cathodes, molybdenum doped with either a single rare earth oxide such as $\mathrm{La}_{2} \mathrm{O}_{3}, \mathrm{Y}_{2} \mathrm{O}_{3}$ and $\mathrm{Sc}_{2} \mathrm{O}_{3}$ or a mixture. It has been shown that carbonization greatly improve the emission properties of the cathodes [11]. The vacuum carbonizing process was introduced in the 1970's, and the expected advantages were carburizing time reduction, high quality and pollution free. This process, mainly using methane or propane gas. The major problem with propane gas is the formation of soot. So an acetylene gas was developed recently without sooting problem. This new technology is called acetylene vacuum carburizing process $[12,13,14,15]$. Acetylene is proved to be a promising hydrocarbon used in thermal carbonization process for porous silicon to produce silicon carbide $[16,17,18,19,20]$.

The present work was concentrated on a thoriated tungsten cathodes meshes used in broadcasting transmitting electronic tubes .These cathodes were manufactured using a method that gave a consistently results.
The new cathodes sizes were accurately measured and carbonized The results of distortion treatment was successfully achieved using a home made vacuum chamber for these purpose.

\section{Apparatus Description:}

The main vacuum chamber shown in figure (1) was specially designed for the carbonization process of the present work .This chamber $(\mathrm{L}=100 \mathrm{~cm}$, diameter $=50 \mathrm{~cm})$ made of stainless steel and cooled by chilled water $\left(5-10^{\circ} \mathrm{C}\right)$ supplied from main chiller. The chamber is connected to a vacuum system satisfying pressure around $\left(10^{-5}-10^{-6} \mathrm{mbar}\right)$ using diffusion and rotary pumps. The pressure is measured by penning and pirani gauges. This chamber is also supplied with a feed- through on both sides for the electrodes. They are also cooled with chilled water .These electrodes are used to supply the cathode with high current and low voltage from an AC power supply. The temperature was measured by an optical pyrometer through side entry quartz window .There is an inlet for the hydrocarbon (liquid benzene) with needle valve located in between the chamber and the bubbling enclosure. The system is also equipped with a computer through an interface to control the deposition parameters (T, P, t, I and V). 


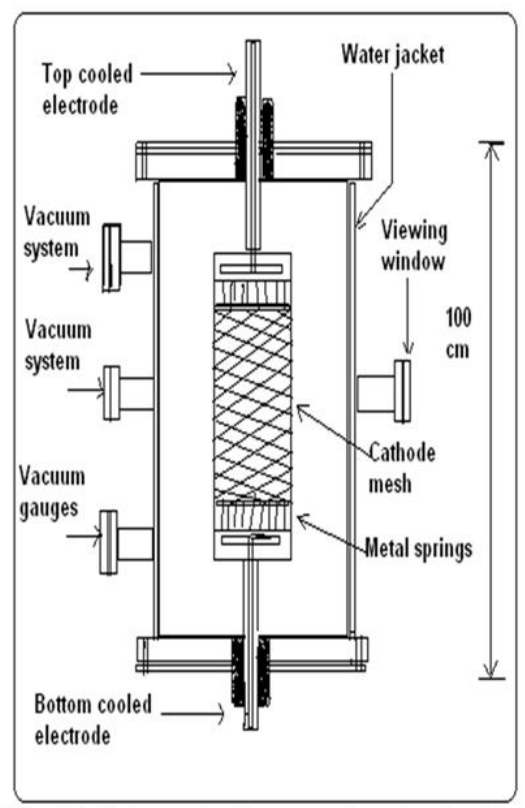

Fig.(1): Schematic diagram of carbonization chamber used in this work.

\section{Carbonization Results And Discussion Of(2 \% $\mathrm{ThO}_{2}$-W)Cathode :}

Vacuum carbonizing furnace was developed for the carbonizing thoriated tungsten cathodes meshes as shown in figure ( 1 ) . The cathode mesh was manufactured from $(0.4 \mathrm{~mm}) \mathrm{W}$ - wires using the mandrel shown in figure ( 2 A ). These meshes were spot welded around the wire crosses. This is shown in figure $(3)$. The principle of carbonization process depends on the heating of the raw cathode to temperature range around $1800^{\circ} \mathrm{C}$ $1900^{\circ} \mathrm{C}$ by passing an electrical current in vacuum at pressure about $10 \mathrm{mbar}$ or less in order to prevent oxidation of thoriated tungsten metal .Then hydrocarbon vapor from benzene introduce into the chamber. The benzene vapor reaches to a high temperature cathode .This process produces carbon atoms due to cracking the benzene vapor to produce carbon atoms. These produced carbon atoms deposited on the new manufactured cathode mesh which is fixed as shown in figure (1) which must be heated in vacuum and maintain at constant temperature around $1800^{\circ} \mathrm{C}$. After the deposition, the carbon atoms will diffuse from the surface into the tungsten wire and react with it to create a tungsten carbide at a certain depth of the wire surface. This process will increase its lifetime and also improve their working characteristics used in high power electronic tubes. The carbonization system in this work was equipped with a computer system. This system was used to controlled the main deposition parameters like temperature, vacuum pressure, time, current and voltage. These will make the process easy, especially when the carbon atoms started to deposited and diffuse .These conditions were varies from one experiment to another. The programmable temperature was calculated according to Stephan'sBoltzman relation.

The carbonization percentage value has the effect on the emission properties of cathodes . This was determined by the change in the resistance of the cathode before and after carbonization process as follows [12] :

$$
\mathrm{C} \%=(\mathrm{R} 2 \mathrm{R} 1) / \mathrm{R} 1
$$

Where $R_{1}$ and $R_{2}$ are the resistance of the wire before and after carbonization respectively. The experimental measurements of $R_{1}, R_{2}$ from figure (4) and the calculated $(\mathrm{C} \%)$ ) for thoriated tungsten cathode with wire diameter $(0.4 \mathrm{~mm})$ are :

$\mathrm{R}_{1}=5.7 \mathrm{~m} \Omega ; \mathrm{R} 2=8.1 \mathrm{~m} \Omega ; \mathrm{C}=0.42 \%$. This result should be the optimum degree of carbonization obtained in this work. This process creates an outer skin of tungsten carbide on the wire and facilitates the reduction of the thorium oxide to metallic thoria, stabilizes the surface resistance of the cathode to gas poisoning 


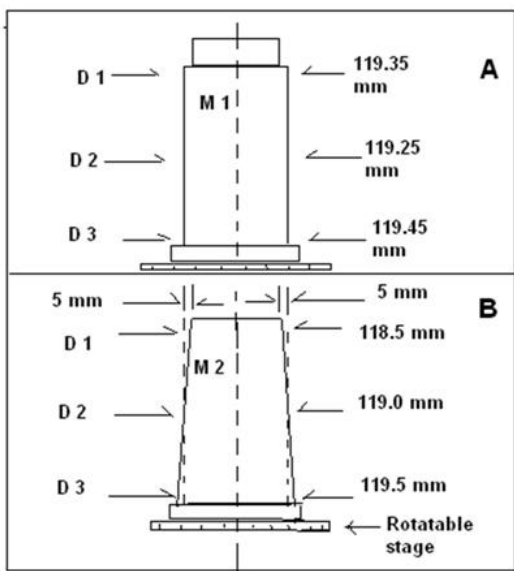

Fig. (2): Schematic diagram of cathode mandrel; A) before, and B) after distortion treatment .

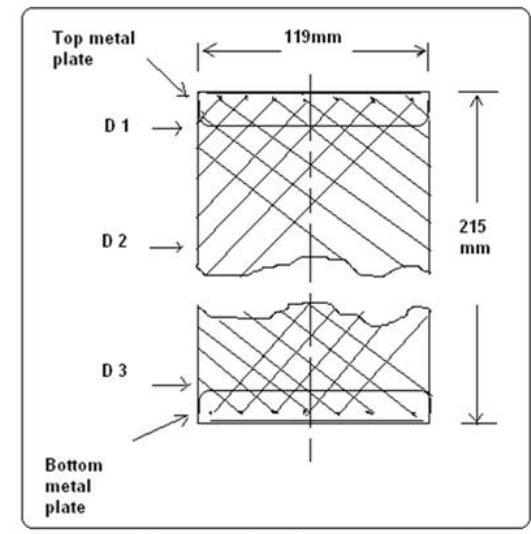

Fig. (3): Schematic diagram of cathode mesh type (CQS200).

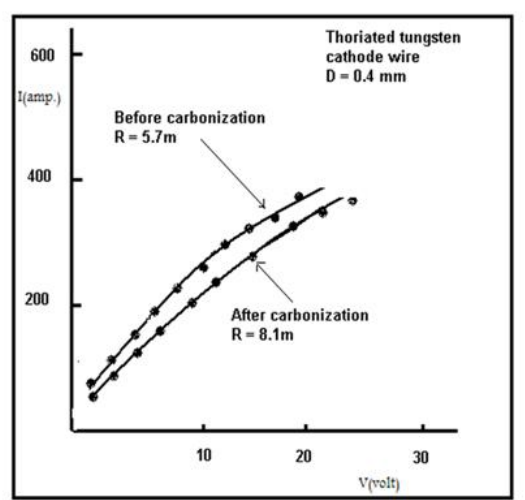

Fig. (4): shows current versus voltage
Distortion Treatments Results And Discussion For Cathodes :

The distortion of the cathodes is one of the major problems which appear after the carbonization process. This reveals as size deviations through the cathode dimensions and distortions will cause an assembled problem in the fixation inside the electron tube. Figure (1) shows the position of the cathode inside the carbonization chamber .The dimensions of the electronic tube cathode type (CQS200) and their measurement points are indicated in figure (3). The dimension of this cathode was measured by using an accurate enlarger projector (40x) with accuracy of one micron . So the measurements are explained as in the following procedure:

a) The cathode was laid horizontally above the enlarger table and then adjusted at zero level along $\mathrm{x}, \mathrm{y}$ and z. .

b) Measurements at three points of the cathode along the mesh axis were started from the top, intermediate and bottom regions as indicated in figure (3).

c) The diameters at three regions mentioned in( c) were measured three times at different angles $\left(\theta_{1}=\right.$ $0.0^{\circ}, \theta_{2}=45^{\circ}$, and $\theta_{3}=90^{\circ}$ ), then the average value was calculated

d) The diameters were calculated at each angle mentioned in (d) using the relation :

$D_{\mathrm{x}}\left(\theta_{\mathrm{x}}\right)=\mathrm{D}_{\mathrm{m}}-2\left(2 \mathrm{D}_{\mathrm{w}}\right) \ldots(2)$

Where $D_{\mathrm{x}}$ : $\left(\theta_{\mathrm{x}}\right)$ is the calculated diameter at $\left(\theta_{\mathrm{x}}\right)=0.0^{\circ}, 45^{\circ}$ and $90^{\circ}$ when $\mathrm{x}=1,2,3$.

$\mathrm{D}_{\mathrm{m}}$ : is the measured diameter of the new manufactured cathode.

$\mathrm{D}_{\mathrm{w}}$ : is the measured wire diameter of the cathode.

Therefore, the average diameter $D_{x}$ (av.) for each region can be calculated using the relation: 
$\mathrm{D}_{\mathrm{x}}(\mathrm{av})=.1 / 3\left[\mathrm{D}_{1}\left(\theta_{1}=0.0^{\circ}\right)+\mathrm{D}_{2}\left(\theta_{2}=\right.\right.$ $\left.45^{\circ}\right)+\mathrm{D}_{3}\left(\theta_{3}=90^{\circ}\right]$

Where $D_{x}(a v$.$) : is the average$ diameter at $\mathrm{x}$.

Now the diameter deviation for each region can be calculated from the relation:

$\Delta \mathrm{D}_{\mathrm{x}}(\mathrm{av})=.\mathrm{D}_{\mathrm{x}}(\mathrm{av})-.\mathrm{D}_{\mathrm{c}}$

$\mathrm{D}_{\mathrm{c}}$ : is the real diameter of the cathode $\left(\mathrm{D}_{\mathrm{c}}=119 \mathrm{~mm}\right)$.

The dimension of the cathode was investigated after the manufacturing and carbonization processes using the methods mentioned above. Table (1) shows the measured cathode dimensions and their deviations after the carbonization. The carbonization process produces a conical cathode shapes. The cathode mesh in figure (3) shows a shrinkage of the intermediate diameter $\left(\mathrm{D}_{2}\right)$ and a diameter increased of the lower region $\left(\mathrm{D}_{3}\right)$ within $(1-2$ $\mathrm{mm}$ ) as a function of the carbonization parameters ( temperature and time).

The interesting problem which is relating to any heating process of metal wires like tungsten is the distortion at high temperatures around $2000^{\circ} \mathrm{C}$. The high power electronic tube working at $200-500 \mathrm{kw}$, always suffering from cathode distortion. This cathode also suffers from distortion during the heating process before and after the carbonization. The present work will concentrate on the treatment of this distortion phenomena results due to high temperature carbonization process for $\left(2 \% \mathrm{ThO}_{2}-\mathrm{W}\right)$ cathode mesh. The distortions effects previously mentioned were treated to keep it as minimum as possible according to the present work as follow:

Firstly; it was used a metal springs in a strip shape to fix the cathode inside the carbonization chamber to give it more flexibility along the vertical axis.

Secondly; manufacturing new cathode mandrel with conical shape instead of cylindrical shape to overcome the separation as shown in figure (2B) .

Thirdly; the cathode was overturned inside the chamber after the carbonization process and exposed to a heating process many cycles in order to remove the residual deviation along the cathode.

Table (1): The measurement positions for mandrel M1 from (fig. 2A).

\begin{tabular}{|c|c|c|c|c|c|c|}
\hline \multirow{4}{*}{$\begin{array}{c}\text { Cathode } \\
\text { Resistance } \\
(\mathrm{m} \Omega \text { ) } \\
4.25 \\
4.25 \\
4.15\end{array}$} & $\begin{array}{c}\text { Cathode } \\
\text { No. }\end{array}$ & $\begin{array}{c}\text { Wire } \\
\operatorname{dim} .(\mathrm{mm})\end{array}$ & $\begin{array}{c}\text { Cathode } \\
\text { length } \\
(\mathrm{mm})\end{array}$ & $\begin{array}{c}\Delta \mathrm{Dl} \\
(\mathrm{mm})\end{array}$ & $\begin{array}{c}\Delta \mathrm{D} 2 \\
(\mathrm{~mm})\end{array}$ & $\Delta \mathrm{D} 3(\mathrm{~mm})$ \\
\hline & 50 & 0.5 & 26.3 & 0.143 & 0.220 & 0.254 \\
\hline & 54 & 0.5 & 27.0 & 0.128 & 0.180 & 0.397 \\
\hline & 55 & 0.5 & 27.4 & 0.213 & 0.190 & 0.288 \\
\hline$((A v=0.5 \mathrm{~mm}))$ & & & & 0.161 & 0.197 & 0.313 \\
\hline 6.6 & 56 & 0.4 & 27.8 & 0.041 & 0.061 & 0.271 \\
\hline 6.45 & 57 & 0.4 & 27.5 & 0.170 & 0.040 & 0.210 \\
\hline 6.45 & 58 & 0.4 & 27.5 & 0.170 & -0.270 & 0.270 \\
\hline$((\mathrm{Av} .=0.4 \mathrm{~mm}))$ & & & & 0.127 & ------ & 0.250 \\
\hline & & & & 0.144 & +----- & 0.282 \\
\hline
\end{tabular}

Table (2) shows the necessity of the spring strips .The cathode dimension was measured after the carbonization process to investigate the residual distortion. Table (3) shows the experimental results for cathode using the previous distortion treatment methods. This method produces successful experimental results for high vacuum electronic tubes operation. 
Table (2): Results of cathodes produced from normal mandrel M1 from (fig. 2A).

\begin{tabular}{|c|c|c|c|c|c|c|c|}
\hline & \multicolumn{3}{|c|}{ Before carbonization } & \multicolumn{3}{|c|}{ After carbonization } \\
\hline $\begin{array}{c}\text { Cathode } \\
\text { No. }\end{array}$ & $\begin{array}{c}\text { Fixing } \\
\text { type }\end{array}$ & $\begin{array}{l}\Delta \mathrm{Dl} \\
(\mathrm{mm})\end{array}$ & $\begin{array}{l}\Delta \mathrm{D} 2 \\
(\mathrm{~mm})\end{array}$ & $\begin{array}{l}\Delta \mathrm{D} 3 \\
(\mathrm{~mm})\end{array}$ & $\begin{array}{l}\Delta \mathrm{Dl} \\
(\mathrm{mm})\end{array}$ & $\begin{array}{l}\Delta \mathrm{D} 2 \\
(\mathrm{~mm})\end{array}$ & $\Delta \mathrm{D} 3(\mathrm{~mm})$ \\
\hline 49 & A & |------ & ------ & ------ & 0.050 & 0.450 & 1.563 \\
\hline 50 & $\mathrm{~B}$ & 0.143 & 0.220 & 0.254 & 0.353 & 0.003 & 0.792 \\
\hline 52 & B & -0.633 & 0.105 & 0.163 & -0.394 & 0.360 & 1.228 \\
\hline 53 & $\mathrm{C}$ & -0.083 & 0.135 & 0.613 & -0.925 & -0.140 & 0.948 \\
\hline 54 & $\mathrm{C}$ & 0.128 & 0.180 & 0.397 & -0.120 & 0.590 & 1.340 \\
\hline 55 & $\mathrm{~B}$ & 0.213 & 0.190 & 0.288 & 0.740 & 1.180 & 1.890 \\
\hline 58 & B & 0170 & -0.270 & 0.270 & 1.250 & 1.440 & 1.800 \\
\hline
\end{tabular}

A: cathodes fixing using similar spring strips on both sides.

B: cathodes fixing using different spring strips on both sides.

$\mathrm{C}$ : cathodes fixing without using spring strips, but using metal connectors.

Table (3): Results of Cathodes produced from a modified mandrel M2 (fig. 2B).

\begin{tabular}{|c|c|c|c|c|c|c|c|c|c|c|}
\hline \multirow[b]{2}{*}{$\begin{array}{l}\text { Cathode } \\
\text { No. }\end{array}$} & \multirow[b]{2}{*}{$\begin{array}{c}\text { Fixing } \\
\text { type }\end{array}$} & \multicolumn{3}{|c|}{ Before carbonization } & \multicolumn{3}{|c|}{ After carbonization } & \multicolumn{3}{|c|}{ After treatment } \\
\hline & & $\begin{array}{l}\Delta \mathrm{D} 1 \\
(\mathrm{~mm})\end{array}$ & $\begin{array}{c}\Delta \mathrm{D} 2 \\
(\mathrm{~mm})\end{array}$ & $\begin{array}{c}\Delta \mathrm{D} 3 \\
(\mathrm{~mm})\end{array}$ & $\begin{array}{c}\Delta \mathrm{D} 1 \\
(\mathrm{~mm})\end{array}$ & $\begin{array}{c}\Delta \mathrm{D} 2 \\
(\mathrm{~mm})\end{array}$ & $\begin{array}{c}\Delta \mathrm{D} 3 \\
(\mathrm{~mm})\end{array}$ & $\begin{array}{c}\Delta \mathrm{DD} 1 \\
(\mathrm{~mm})\end{array}$ & $\begin{array}{c}\Delta \mathrm{D} 2 \\
(\mathrm{~mm})\end{array}$ & $\begin{array}{c}\Delta \mathrm{D} 3 \\
(\mathrm{~mm})\end{array}$ \\
\hline 61 & C & -0.4 & -0 & 0. & -0.700 & -0.3 & 0.652 & -0.110 & 0.140 & -0.075 \\
\hline 65 & C & -0.350 & -0.240 & 0.210 & -0.200 & -0.040 & 0.290 & 0.500 & 0.160 & 0.150 \\
\hline
\end{tabular}

\section{Conclusions:}

The manufacturing, carbonization and distortion treatments of cylindrical cathodes for electronic tubes were successfully achieved and seem to have appropriate design for controlling the geometrical shapes and dimensions, specially the mean diameter (designed diameter) at the final stage. The other conclusions of the present work are :

1). The cylindrical cathode was manufactured in tapered profile and the smallest diameter was located at the bottom side during the heating process. 2). The difference between the tapered diameters depends upon the design diameter size and cathode length.

3). The number of cathode distortion treatments processes were directed us to the final geometrical shape of cathode within a minimum average deviation values between $0.4-0.5 \mathrm{~mm}$.

\section{References:}

1.Fox , D.B. 1989. U. S.Patent 4810925. Directly heated cathodes.

2.Misumi and Akira .1978. U. S. Patent: 4081713. Directly heated oxide cathode.
3.David, G. and Williams P.C. 1997. Linear accelerators for radiation therapy, Published by CRC press , $2^{\text {nd }}$ ed. ,England, pp. 37-63.

4.Morgan J. 2003. Valves Amplifiers., Published by Newnes, $3^{\text {rd }}$ ed. Australia , pp. 259-289.

5.Mark, J.T. and McNees S.G.. 1988. New high efficiency $500 \mathrm{~kW}$ tetrodes for short wave broadcast. Broadcasting IEEE Transactions on .,34 (2), : 144-146.

6.Poret , F. and Roquais ,J.M. 2005. The base metal of the oxide cathode. Applied Surface Science, 251: 31-41.

7.Andre,B. and Paul, T. 1989.U.S. Patent: 4836816. Method of treating tungsten cathodes.

8. Bague, P. , Morizot, P.and esgardin , G.D. 1994. J.Phys. D.Appl. Phys. 27,402 .

9.Jame ,E.P. 1993. Operation of thoriated tungsten cathodes. AIP Conf. Proc. 271 : 1435-1446.

10. Zhou, M., Chen, Z. and Zhang, J. 1994. High Temp. High Press, 26 , 145. 
11. Wang ,J. et. al., 2005.Emission efficiency optimization of $\mathrm{Re}_{2} \mathrm{O}_{3}$ doped molybdenum thermoionic cathode by application of pattern recognition method Applied Surface Science, $251: 89-96$.

12. Iwata Hitoshi, 2005.Advanced acetylene vacuum carburizing. IHI Engineering Review. 38(2):83-88.

13. Kubota, K. et al , 1996. High quality, Vacuum carburizing process with acetylene., The Japan Hociety for Heat Treatment ,The 43th Lecture Rally Outline Collection :3-4.

14. Sugiyama, M. et al, 1998. Vacuum carburizing with acetylene .Proceeding of $18^{\text {th }}$ ASM Heat Treating Society Conference: 2933 .

15. Okumura, N. 1998.Vacuum carburizing process by acetylene, Heat Treatment, 38: 94-197.

16. Mikko, B., Jarno, S. and Ensio,L. 2004. Humidity behavior of thermally carbonized porous silicon. Applied Surface Science, 222:269-274.

17. Salonen, J. and Laine,E. 2002. Thermal carbonization of porous silicon surface by acetylene. J. of Applied Physics , 91 (1):456-461.

18. Hashim, A.M., and Yasui,K.,2008. Carbonization layer obtained by acetylene reaction with silicon (100) and (111) surface using low pressure CVD,Journal of Applied Sciences, 8(19) : 3473-3478.

19. Muller, St. G., et al., 2006. Large area $\mathrm{SiC}$ substrate and epitaxial layer for high power semiconductor devices: An industrial perspective. Superlattices Microstruct, $40: 195$ 200.

20. Tamura , K., et al., 2008. Growth $\mathrm{GaN}$ on $\mathrm{SiC} / \mathrm{Si}$ substrate using AIN buffer layer by hot mesh CVD. Thin Solid Film, 516 : 659-662.

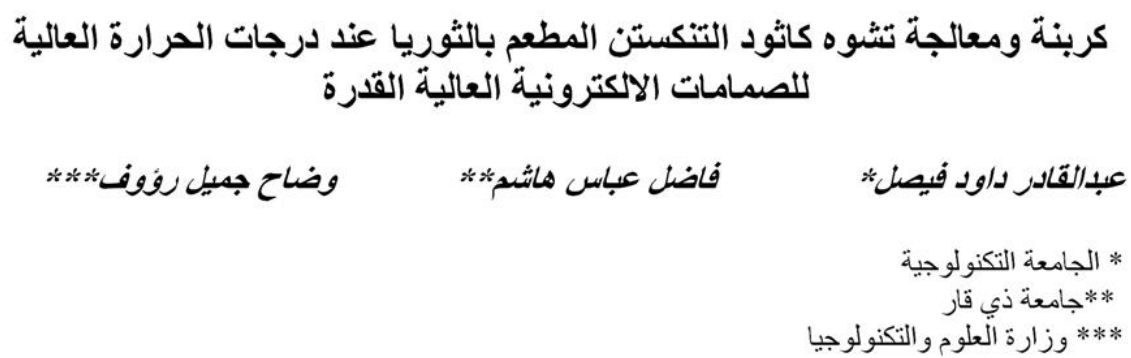

يهدف البحث الى تثكيل وكربنة ومعالجة التشوهات الناتجة بعد الكربنة لكاثودات الصمامات

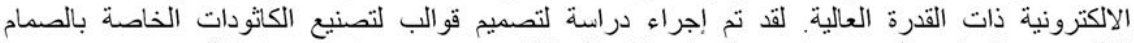

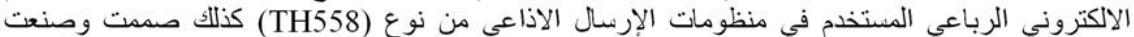

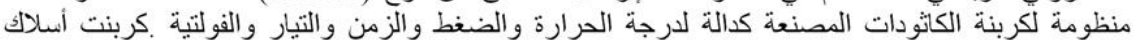

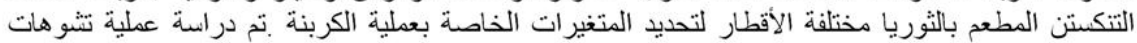

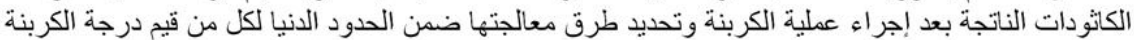

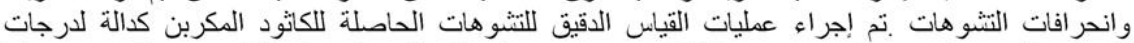

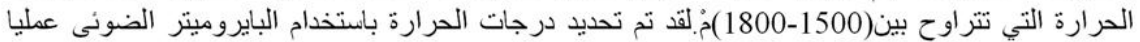

